\title{
Potential Bonds between Extroversion/Introversion and Iranian EFL Learners' Listening Comprehension Ability
}

\author{
Parviz Alavinia (Corresponding author) \\ Faculty of Humanities and Letters, Urmia University \\ Vajfajr 2 Blvd., Urmia, West Azerbaijan, Iran \\ Tel: 98-0441-336-2008 E-mail: pevinia2006@yahoo.com
}

\author{
Abdolraoof Sameei \\ Urmia Islamic Azad University \\ Salmas Blvd., Urmia, Iran \\ Tel: 98-0441-271-9900Ｅ-mail: raoof_1351@yahoo.com
}

Received: January 26, 2012

Accepted: February 29, 2012

Published: May 1, 2012

doi:10.5539/elt.v5n5p19

URL: http://dx.doi.org/10.5539/elt.v5n5p19

\begin{abstract}
The present study was implemented to investigate the possible relationship between introversion/extroversion and the listening ability of intermediate Iranian EFL (English as a Foreign Language) learners by taking into account their gender, age, and grades of study. A total of 120 Intermediate learners (62 males and 58 females) studying at Shokoh-e-Andishe Language Institute in Sardasht participated in the current study. The subjects were asked to fill the EPQ (Esyneck Personality Questionnaire) to be categorized as either introvert or extrovert. To test the research hypotheses set forth in the present study, Pearson correlation coefficient and two-way analysis of variance were run as the main statistical analyses. The results indicated that there was a significant relationship between listening ability of subjects and the personality characteristic in question, i.e. extroversion vs. introversion. The scores of listening ability had a positive relationship with the introversion of subjects, that is, the more introvert the subjects, the better their performance on listening. However, as the findings revealed, no significant interaction relationship was found between gender and introversion/extroversion on the one hand and listening ability of subjects on the other; yet, there was a significant interaction relationship between introversion/extroversion and the participants' age and grades of study, on the one hand and their listening ability, on the other.
\end{abstract}

Keywords: Eysenck Personality Questionnaire (EPQ), Extroversion, Intermediate Iranian EFL learners, Introversion, Listening comprehension

\section{Introduction}

\subsection{Foreword}

Among the pivotal issues of considerable concern in EFL (English as a Foreign Language)/SLA (Second Language Acquisition), one can refer to the possible linkages between personality characteristics and language learning. Though a plethora of varied factors are involved in the intricate process of language learning, learner variables and individual differences have always been in the foreground of attention of psycholinguists and psychometricians. As factors like these are regarded to be of prime salience in the macro-level analysis of learning processes, a growing amount of heed is being given to an examination of such variables. Indeed, one of the major preoccupations of the present-day researchers is coming up with clear-cut answers to questions like why language learners who enjoy similar backgrounds are found to acquire a second language with varying degrees of success.

Even though a multitude of learner variables such as gender, age, family background, socio-psychological factors like motivation and attitude, cognitive styles like field-independence and field-dependence, personality-induced variables like self-esteem and anxiety are thought to be in a sort of ongoing interplay with second language learning processes and outcomes, it is the last category, i.e. personality variables, which is posited, in the present study, to be of a more crucial role in the course of language learning. Hence, among the manifold personality factors, the researchers have opted for the analysis of one of the paramount dichotomous cases widely known as introversion/extroversion, and its would-be go-togetherness with the learners' listening ability. 


\subsection{Statement of the Problem}

As far as language assessment is concerned, many variables should be considered. For instance, as a teacher who aims to assess the listening ability of students, one should be aware that this skill depends on many variables, among which the personality characteristics may be the most important ones. As was stated earlier, the present study is after finding the possible relationship between introversion/extroversion, on the one hand and the learners' listening comprehension ability, on the other. In so doing, yet, the role of other potentially significant factors and learner characteristics such as gender, age, and grade of study is also taken into account. Another major concern of the researchers in the current study is that of reminding language teachers that being aware of students' personal characteristics (biological, psychological, emotional, etc.) is a very important aspect of language teaching methodology and consequently language assessment.

\subsection{Significance of the Study}

Though most educators are currently well-informed of the fact that different individuals have recourse to different ways and strategies for absorbing, processing and retaining new information and skills, they still have a tendency to implement a single and uniform teaching method for instructing a heterogeneous class of diverse learners with disparate talents, hoping that one size would ultimately fit all. This lack of concern for individual preferences, differences and needs might be taken as part of the explanation for why many language-related problems of students have gone and continue to go unnoticed on the part of language instructors and evaluators.

In effect, in the absence of a full-fledged reappraisal of such learner variables, there might exist the hazard of believing that the way we instruct our learners is the most efficient way and consequently we are liable to bias our teaching in favor of students who approach the learning in much the same way we do. Thus, through a partially in-depth analysis of the role of introversion/extroversion and its viable bonds with the learners' listening ability, the researchers in the present study hope to raise teachers' awareness of such important learner characteristics and individual differences and by way of doing so, they aim to help instructors diagnose some of their students' personality-induced difficulties.

Despite the fact that a multitude of research projects have strived to address the notion of introversion/extroversion from a range of varied perspectives (e.g. Bonner, et al., 2007; Salehi, 2010; Mitchell, et al., 2011), a fleeting glimpse through the literature on the issue reveals that most of the studies addressing the effect of introversion and extroversion (e.g. Busch, 1982; Shackleton \& Fletcher, 1984), have tried to find the impact of this personality trait on facets like speaking ability and verbal fluency. Thus, in order to take a somewhat unique approach to the study of this well-established learner variable, the present study grapples to explore the probable impact of introversion/extroversion on listening ability of Iranian EFL learners. In so doing, the researchers will also concern themselves with the potential interpolation of other intervening variables such as gender, age and grade of study.

\subsection{Research Questions and Hypotheses}

To be able to come up with straightforward justifications as to the problem postulated in the current study the following research questions were set forth:

1. Is there a significant relationship between Introversion/Extroversion and the listening ability of intermediate Iranian EFL learners?

2. Does gender variation exert any significant effect as to the relationship between Introversion/Extroversion and the listening ability of intermediate Iranian EFL learners?

3. Does age variation exert any significant effect as to the relationship between Introversion/Extroversion and the listening ability of intermediate Iranian EFL learners?

4. Do learners' grades of study exert any significant effect as to the relationship between Introversion/Extroversion and the listening ability of intermediate Iranian EFL learners?

In line with the above research questions, the following hypotheses were formulated:

1. There is no significant relationship between Introversion/Extroversion and the listening ability of intermediate Iranian EFL learners.

2. Gender variation does not exert any significant effect as to the relationship between Introversion/Extroversion and the listening ability of intermediate Iranian EFL learners.

3. Age variation does not exert any significant effect as to the relationship between Introversion/Extroversion and the listening ability of intermediate Iranian EFL learners.

4. Learners' grades of study don't exert any significant effect as to the relationship between Introversion/Extroversion and the listening ability of intermediate Iranian EFL learners. 


\section{Literature Review}

\subsection{Personality: An Important Individual Difference}

One of the most significant characteristics of human beings is that each individual is a sui generis amalgam of feelings, mentality, concepts, aims and reactions. This list can be extended to hundreds of terms if coverage of all the complexities of personality is needed. These combinations create the individuality that every individual enjoys (Wright et al., 1970). Differences among individuals create reasons for negotiations, arguments, and discussions and lead to the development of humanity as a whole. Knowledge of the backgrounds lying behind these differences enhances the flexibility and understanding of the different individuals (Skehan, 1989). It is assumed that having more awareness of theories of individual differences and an ability to incorporate them in the teaching process should enable teachers to help their learners enjoy their listening and get more out of it. Moreover, learners should be aware of themselves, their personalities and listening styles in order to approach the listening process in a constructive way (Shackleton \& Fletcher, 1984). Individual learner differences are the variables that characterize learners and give each one his/her individual uniqueness. The goal of investigating individual differences is to explore the diversity of intellect, forms of cognitive processes, and different mental functions (Skehan, 1989). Example categories used by various researchers (e.g. Ellis, 1994; Skehan, 1989; Eysenck, 1999) for investigating these differences are personality, learning styles, motivation, intelligence, autonomy, learning strategies, gender, age, language aptitude, anxiety, affective states, and need for power.

Personality is considered as a very important category of individual differences since the individual is often judged depending on her/his personality. Personality refers to the partially stable and long-lasting facets of an individual which distinguish him from other people, and form the basis of our predictions concerning his future behavior (Wright et al., 1970). Therefore, it is expected that any given individual will behave in a reasonably consistent manner on different occasions. Those who study human personality are often interested in individual differences. They assume that there are considerable individual differences in personality and that these differences will be revealed by differences in behaving and reacting in a given situation (Eysenck, 1985). That is why one feature common to the majority of personality theories is the emphasis on the individual. Researchers, during the last few decades, have done a lot of work in order to find a comprehensive definition of personality. Personality can be defined on many levels like educational, psychological, and social. At the level of teaching and learning, we are looking for those aspects of personality that affect the nature and the quality of learning process. In this study, definitions of personality are presented, looking at the personality dimensions from a psychological point of view. The researchers try to review the theories and hypotheses that deal with personality, especially Eysenck's distinction between personality 'types' and personality 'traits'. Aimed at exploring personality factors in EFL/SLA, the researchers found that most of the literature focuses on two dimensions of personality, closely related to the learning process; and these are extroversion/introversion and risk-taking.

\subsection{Extroversion vs. Introversion}

In personality psychology, a consensus has emerged that the most important differences in personality can be reduced to combinations of 5 basic dimensions, known as the 'big five' (Ely, 1983; Komarraju \& Karau, 2005; Allik, et al., 2010), which are said to be derived by several independent factor analyses of very large numbers of personality variables. The most important of these is the renowned dichotomy of introversion/extraversion. Intuitively, extroverts are characterized as outgoing, gregarious and fun-loving, whereas introverts are seen as more quiet, reserved and pensive. To this intuitive distinction between types of social behavior, Eysenck (1999) has added a biological dimension. According to Eysenck's theory, which has been confirmed by a number of experimental findings (Heyde, 1991), introverts are characterized by a higher level of intrinsic activation or arousal in the brain cortex. As any individual operates ideally with a moderate level of cortical arousal, the more extroverted will be inclined to look for external stimulation to reach an optimal level, whereas the more introverted people would rather try to avoid strong stimuli in order not to raise their activation level too much. This means that typical introverts are highly sensitive, reacting strongly to relatively mild stimulation, whereas typical extroverts are excitement-seekers, with a much higher endurance for loud noise, strong light, and other forms of external stress. Extroverts and introverts also seem to have different reminiscence capabilities (Eysenck, 1999). Reminiscence is due to consolidation of the memory trace. This consolidation, which is a direct function of cortical arousal, has been proven to be stronger in the introverts, at least in the long run (after more than 30 minutes). Extroverts, on the other hand, tend to show better memory and greater reminiscence 'in the short run' (Eysenck, 1985).

Since extroverts are more talkative and prone to start a conversation, they are usually expected to be better language learners than introverts. Language researchers were extremely disappointed when it appeared that extroversion did not correlate with language test results (Naiman, et al., 1978). For two decades this finding was quoted, but never 
challenged, in applied linguistic studies (Ely, 1983). This negative publicity was so strong that many researchers (e.g. Skehan, 1989) seemed to believe that no significant link could be expected between extroversion and any linguistic measure. However, when we look at language formality rather than grammatical correctness scores, a clear relationship emerges. Ely (1983), reviewing the literature on language and personality (for native English speech), estimates that introverted speakers are likely to use a more formal style, characterized by a higher proportion of nouns, adjectives and prepositions, and a lower proportion of pronouns, verbs and adverbs.

On the other hand, extroverts' speech seems more fluent than that of introverts. One should be careful in one's definition of fluency, though, as different measures may lead to different results (Pierce, 1996); measures including lexical richness would tend to benefit the introverts. A possible interpretation of these results is that introverts would spend more time reflecting before they speak, whereas extroverts would be quicker to react, avoiding pauses in the conversation. Eysenck (1999) notes that introverts are more thoughtful than extroverts, taking more heed of the maxim that one should be sure brain is engaged before putting mouth into gear. This would follow from the extroverts' need for the recurrent stimulation that a conversational interaction provides, and the introverts' preference for undisturbed, inner reflection. The longer time spent on reflection would make the introvert's speech more precise and richer in distinctions, but less fluent and less reactive to the immediate context of the conversation. This also fits in with the introverts' better long term memory allowing them to retrieve more accurate descriptions, while the extroverts' better short term memory allows them to react and speak more quickly.

Most people believe that an extrovert is a person who is friendly and outgoing. While that may be true, that is not the true meaning of extroversion. Basically, an extrovert is a person who is energized by being around other people. This is the opposite of an introvert who is energized by being alone. Extroverts tend to 'fade' when alone and can easily become bored without other people around. When given the chance, an extrovert will talk with someone else rather than sit alone and think. In fact, extroverts tend to think as they speak, unlike introverts who are far more likely to think before they speak. Extroverts often think better when they are talking. Concepts just don't seem real to them unless they can talk about them; reflecting on them isn't enough. Their ability to make small talk makes them appear to be more socially more adept than introverts, although introverts may have little difficulty talking to people they don't know if they can talk about concepts or issues (Ely, 1983).

\section{Method}

\subsection{Participants}

The participants of the current study were initially 140 male and female Iranian intermediate learners of English, studying in Shokouh Language Institute, Sardasht. The reason for the inclusion of both male and female students was to examine the influence of gender on learners' listening proficiency. In other words, one of the focal issues of concern in the present study was to see whether learners' gender affects their listening ability or not. The participants' age ranged from 8 to 22; as is shown in Table 1 and Figure 1, 25\% of subjects (30 learners) were between 8 to 10 , $25.8 \%$ ( 31 learners) were between 11 to $14,27.5 \%$ (33 learners) were between 15 to 18 , and $21.7 \%$ ( 26 learners) were between 19 to 22 years of age. Further, the partakers enjoyed a variety of educational backgrounds, i.e. the study population was composed of elementary (two classes), guidance school (two classes), high school (one class) and university students (one class). As Table 3 and Figure 3 help reveal, 26.7\% of subjects (32 learners) were in elementary level, $24.2 \%$ (29 learners) studied at guidance school, 25.8\% (31 learners) came from high school, and $23.3 \%$ (28 learners) were university students.

In order to be included in the final subject pool, participants were requested to attend all phases of the study. However, 20 participants were not qualified enough to be included in the analysis and were consequently eliminated from the total sample, mainly on account of the following considerations: (1) failure to produce clear answers, or (2) deviating from instruction and standards of the test. Accordingly, out of the original pool of 140 participants, merely 120 (62 males and 58 females) were found qualified to be included in the final analysis of data. Thus, based on what is illustrated in Table 2 and Figure 2, 51.7\% of the participants (62 learners) were males and $48.3 \%$ (58 learners) were females.

Successive to data collection, the participants were grouped on the basis of gender, age levels, and grades of study. The reason for this grouping was to account for the study hypotheses, i.e. the effect of introversion/extroversion on the listening ability considering the learners' gender, age and grades of study.

\subsection{Instrumentation}

To tap the required data, Eysenck's (1999) Personality Questionnaire was administered to learners as the chief data collection instrument, which was aimed at determining which participants were introverts and which ones were extroverts. A TOEFL listening comprehension test was also used to determine the subjects' listening ability. The 
following section is devoted to the provision of an ample description of Eysenck Personality Questionnaire (EPQ) and TOEFL listening comprehension test used in this study.

\subsubsection{Eysenck Personality Questionnaire}

To examine the individual trait in question, i.e. extroversion/introversion, the researchers made use of Eysenck Personality Test (EPQ-R) (Esyneck, 1999), which is the shortened version of the last Eysenck test (1999). This test consists of two criteria known as psychotisim and extroversion/introversion, and a total of 12 yes/no questions is allocated to gauging each criterion. It should be emphasized that the questions used in the current probe are only those which have been developed for determining introversion and extroversion. According to what Eysenck reports in the test manual, the reliability of the questionnaire is $88 \%$ and $84 \%$ (for extroversion and introversion scale) and $61 \%$ and $62 \%$ (for psychotisim scale) for males and females, respectively.

\subsubsection{Listening Comprehension Test}

The listening comprehension test used in the present study was a Test of listening in English, taken from TOEFL Test Preparation Kit. The topic selected for this study was as follows:

'Some people think that television has negative effects such as wasting the students' time to do their school work. Others believe that it is informative. Using the related examples, discuss two positions. Say which position you agree with and give your reasons resulting from the text you listened to.'

Once the listening was over, the learners were required to mention the main points discussed in the conversation, which, in turn, provided the researchers with a lucid indication of the participants' listening proficiency.

\subsection{Design}

As Hatch and Lazaraton (1991) state, when the researcher does not control over the selection and manipulation of independent variables, and when there is no treatment, control group, and control of pre-existing difference among groups, one possibility is the use of ex-post-facto design. As the present study does not deal with cause and effect statement, and control group, treatment, control over variables, it can be concluded that the design of the study is ex-post-facto because we just want to test the psychological variables such as introversion/extroversion with regard to the listening ability of participants and these variables are more or less fixed in the majority of learners.

\subsection{Procedure}

\subsubsection{Administration Procedure}

The following steps were taken in the current study. At the outset of the study EPQ (Eysenck Personality Questionnaire) was administered to the study participants. The researchers made it a point to provide the learners with some hints regarding the answering procedure and the importance of their meticulous responding. The time required for responding the questionnaire was about 15 minutes. The subjects were asked to write their gender, age, and grade of study on the questionnaire. Furthermore, the time interval between the administration of the questionnaire and the listening comprehension test was 10 days. The time allocated for the listening test was about 45 minutes, and, as stated earlier, successive to the listening task the students were asked to write their understanding of the topic in about 100 words.

\subsubsection{Scoring Procedure}

Following the test designer's lead, those participants who answered yes to $2 / 3$ questions out of the whole on the extroversion/introversion scale, were considered as introverts and the rest were grouped as extroverts. Furthermore, regarding the listening comprehension test, the scores were given on the scale of 5, based on the following listening performance checklist adopted from Broukal and Nolan-Woods (1991).

5 Clearly demonstrates competence for listening on both the rhetorical and syntactic levels, though it may have occasional errors.

4 Demonstrates minimal competence in listening on both the rhetorical and syntactic levels.

3 Demonstrates some developing competence in listening but remains flawed on either the rhetorical and syntactic levels, or both.

\section{Suggests incompetence in listening}

1 Demonstrates incompetence in listening

Moreover, to be able to gauge the partially precise proficiency of learners in terms of listening, the researchers resorted to the following five factors in their appraisal, to ensure the final results were as accurate as possible. 
B: Logical Development of ideas

C: Structure

D: Mechanics

E: Rhetoric and syntactic accuracy

It is also worth noting that, in order to ascertain the reliability of listening comprehension test scores, the scoring procedure was carried out by two raters, i.e. one of the researchers and an EFL teacher with an MA Degree in TEFL.

\subsection{Data Analysis}

Having collected the data, the researchers made use of SPSS 16 for data analysis procedure. To test the research hypotheses set forth in the present study, Pearson correlation coefficient and two-way analysis of variance were applied to see whether the interaction relationships are significant. The level of significance for the statistical analysis was set at 0.05 .

\section{Results}

\subsection{Subjects' Introversion and Extroversion}

Table 4 and its corresponding figure (Figure 4) reveal frequency of subjects' introversion and Extroversion. Drawing on the information given there, $44 \%$ of subjects (53 learners) were found to be extrovert and $55.8 \%$ ( 67 learners) were marked as introverts. Moreover, Table 5 depicts the descriptive statistical indices obtained for subjects' introversion and extroversion. As is evident from the table the mean score for introvert subjects equals 16.15 , and the standard deviation relevant to them is 2.205 . On the other hand, the mean score and standard deviation obtained for extrovert subjects are 8.58 and 2.388, respectively. The histogram presented in Figure 5 provides more lucid information regarding introvert and extrovert subjects.

\subsection{Subjects' Listening Comprehension Ability}

The findings pertinent to subjects' listening ability are presented in Table 6 and Figure 6 . Based on the descriptive statistics reported, the mean listening ability for introvert subjects is 4.70 and the standard deviation is 0.668 , whereas the mean listening ability for extroverts equals 1.73 , and the standard deviation is 1.024. The histogram shown in Figure 6 is intended to give out a more vivid elucidation for the readers with regard to the subjects' listening ability.

\subsection{Hypothesis Tests}

\subsubsection{Findings Pertinent to Research Question 1}

1. Is there a significant relationship between Introversion/Extroversion and the listening ability of intermediate Iranian EFL learners?

In order to appraise the relationship between introversion and extroversion and the listening ability of intermediate EFL learners, Pearson Correlation Coefficient was run. As the results shown in table 7 disclose, the Correlation Coefficient calculated regarding the relationship between introversion/extroversion and the listening ability of subjects equals 0.718 , with the level of significance being 0.000 , which, of course, points to the existence of a statistically significant correlation between the two variables in question. Indeed, based on the upshots, introvert subjects were characterized by a better performance on listening ability compared to extrovert subjects.

\subsubsection{Findings Pertinent to Research Question 2}

2. Does gender variation exert any significant effect as to the relationship between Introversion/Extroversion and the listening ability of intermediate Iranian EFL learners?

In order to test the second hypothesis, a Two-way ANOVA was run (see Table 8). Based on the obtained F value and level of significance, the null hypothesis holding that Gender variation does not exert any significant effect as to the relationship between Introversion/Extroversion and the listening ability of intermediate Iranian EFL learners was confirmed.

\subsubsection{Findings Pertinent to Research Question 3}

3. Does age variation exert any significant effect as to the relationship between Introversion/Extroversion and the listening ability of intermediate Iranian EFL learners?

To deal with the third research question of the study, another two-way ANOVA was run (see Table 9), on the basis of which a significant result was encountered with regard to the relationship between listening ability of subjects and their age ranges. As the findings helped reveal, 19 to 22-year-old subjects had the highest scores on listening ability. 
Furthermore, there existed a significant interaction relationship between introversion and extroversion and age ranges, on the one hand and listening ability of subjects, on the other. Faced with this significant result, the researchers also ran an LSD test to find the exact place of difference among the means. Table 10 represents the two by two comparisons made between different ages.

\subsubsection{Findings Pertinent to Research Question 4}

4. Do learners' grades of study exert any significant effect as to the relationship between Introversion/Extroversion and the listening ability of intermediate Iranian EFL learners?

Once more a two-way ANOVA was run (Table 11), to come up with satisfactory upshots regarding the fourth research question. As the findings help unravel, there is a significant difference between listening ability of subjects in the light of their grades of study. Yet, there is no interaction relationship between introversion and extroversion and grades of study, on the one hand and listening ability of subjects, on the other. Table 12 illustrates the results of LSD test, which demonstrated a significant interaction among only the elementary participants and no other groups regarding their grades of study.

\subsection{Discussion}

Based on the findings of the current research, it was revealed that the listening ability of Intermediate Iranian EFL learners significantly correlates with their Introversion/Extroversion (indeed, introvert subjects were found to have a better performance on listening compared to their extrovert counterparts). In what follows, a laconic discussion is provided for the obtained outcomes for each research question.

The first research question addressed the viable relationship between introversion/extroversion and listening ability, and throughout the study it was demonstrated that a significant correlation exists between introversion/extroversion and the listening ability of intermediate Iranian EFL learners. The results further indicated that introvert subjects had a better performance on listening compared to their extrovert counterparts. This finding is in accordance with Busch's (1982) findings, where he concluded that in general extroverted students are less successful in language learning. It should be added that the focus of Busch's study was on pronunciation, whereas the researchers in the present study addressed the listening ability of individuals.

Nevertheless, the upshots gained by Shackleton and Fletcher (1984), partially contradict the present findings, in that these researchers found that extroverts had a better performance apropos verbal fluency tasks. Moreover, Skehan (1989) found that extroverts are better language learners because they would benefit both inside and outside the classroom by having the appropriate personality trait for language learning since learning is best accomplished, according to most theorists, by actually using the target language. Yet, these contradictory findings are not to be taken too seriously, in that they both deal with the oral proficiency not with listening ability which is the main focus of the current study.

The results obtained for the second research question of the study indicated that the interaction relationship between introversion/extroversion and gender, on the one hand and listening ability of subjects, on the other is insignificant. Regarding the third research question, however, a significant relationship was found between introversion/extroversion and age range, on the one hand and the listening ability of intermediate Iranian EFL learners, on the other. 19 to 22-year-old subjects had a privilege in this respect, as they obtained the highest mean score on the listening test. This piece of finding might be attributed to intellectual capabilities and abstract thinking power of older subjects. More precisely speaking, older subjects may possess a wider range of opinions concerning a particular topic, so they might be said to comprehend the subjects more appropriately and cogently.

Finally, data analysis for the last research question revealed that subjects' introversion/extroversion and their grades of study were in a sort of interplay with the learners' listening ability. Yet, the learners' grades of study had nothing to do with the personality characteristic in question, i.e. introversion/extroversion. It must be reiterated, at this juncture, that there existed a significant relationship between the learners' listening ability and their grades of study, i.e. subjects studying in higher grades of study had a better performance over those studying in lower levels. University students had the highest mean score on the listening test.

\section{Concluding Remarks}

Based on the finding obtained, it can be concluded that teachers and educators should not expect students to have the same performance on different language skills in a context where all the external conditions are not the same. To come up with a more precise appraisal of the learners' performance, the psychological differences of students are to be taken into serious account in different instructional arenas. Accordingly, the difference observed among students' scores could be attributable to other differences rather than language ability. Another implication gained through the present scrutiny might be that while assessing the learners' listening comprehension ability, heed must be given to the fact that older students and those studying in higher grades of study are liable to obtain higher scores due to 
factors other than mere language ability. After all, it might be predictable that older students may enjoy more powerful abstract thinking which may lead to more cogent reasoning while listening.

\section{References}

Allik, J., Realo, A., Mottus, R., Esko, T., Pullat, J., \& Metspalu, A. (2010). Variance Determines Self-Observer Agreement on the Big Five Personality Traits. Journal of Research in Personality, 44, 421-426. http://dx.doi.org/10.1016/j.jrp.2010.04.005

Bonner, B. L., Sillito, S. D., Baumann, M. R. (2007). Collective Estimation: Accuracy, Expertise, and Extroversion as Sources of Intra-Group Influence. Organizational Behavior and Human Decision Processes, 103, 121-133. http://dx.doi.org/10.1016/j.obhdp.2006.05.001

Busch, D. (1982). Introversion and Extroversion and the EFL Proficiency of Japanese Students. Language Learning, 32, 32-109. http://dx.doi.org/10.1111/j.1467-1770.1982.tb00521.x

Ellis, R. (1994). The Study of Second Language Acquisition. Oxford: Oxford University Press.

Ely, C. (1983). An Analysis of Discomfort, Risk Taking, Sociability, and Motivation in the L2 Classroom. Language Learning, 36, 1-25. http://dx.doi.org/10.1111/j.1467-1770.1986.tb00366.x

Eysenck, M. W. (1999). Individual Difference: Normal and Abnormal. East Sussex: Lawrence Elbraum Associates. (original work published 1985).

Heyde, A. (1991). The Relationship Between Self-Esteem and Oral Production of a Second Language. Unpublished $\mathrm{Ph}$. D thesis, Ann Arbor: University of Michigan.

Komarraju, M., \& Karau, S. J. (2005). The Relationship between the Big Five Personality Traits and Academic Motivation. Personality and Individual Differences, 39, 557-567. http://dx.doi.org/10.1016/j.paid.2005.02.013

Mitchell, M. E., Lebow, J. R., Uribe, R., Grathouse, H., \& Shoger, W. (2011). Internet Use, Happiness, Social Support and Introversion: A More Fine Grained Analysis of Person Variables and Internet Activity. Computers in Human Behavior, 27, 1857-1861. http://dx.doi.org/10.1016/j.chb.2011.04.008

Naiman, N. M., Frohlich, H., Stern, H., \& Todesco, A. (1978). The Good Language Learner. Research in Education Series, Report No. 7. Toronto: The Ontario Institute for Studies in Education.

Pierce, T. W. (1996). Exploring the Psyche: Introversion and Extroversion. Available from http://geocities.com/Athens/Delphi/6727/expsych.html

Salehi, A. (2010). The Study of Relationship among Personality Factors (Introversion, Extroversion) of Students and their Effects to Selecting a Good Teacher. Procedia Social and Behavioral Sciences, 2, 4016-4020. http://dx.doi.org/10.1016/j.sbspro.2010.03.633

Shackleton, V., \& Fletcher, C. (1984). Individual Differences: Theories and Applications. London: Methuen \& Co.

Skehan, P. (1989). Individual Differences in Second Language Learning. London: Edward Arnold.

Wright, D., Taylor, A., Davies, D. R., Sluckin, W., Lee, S. G. M., \& Reason, J. T. (1970). Introducing Psychology. Harmondsworth: Penguin.

Table 1. The Frequency Distribution of Subjects Regarding Age

\begin{tabular}{|c|c|c|c|}
\hline Age & Frequency & Percent & Cumulative Percent \\
\hline $8-10$ & 30 & 25 & 25 \\
\hline $11-14$ & 31 & 25.8 & 50.8 \\
\hline $15-18$ & 33 & 27.5 & 78.3 \\
\hline $19-22$ & 26 & 21.7 & 100 \\
\hline Total & 120 & 100 & - \\
\hline
\end{tabular}

Table 2. Descriptive Frequency Distribution of Subjects Regarding Gender

\begin{tabular}{|c|c|c|}
\hline Gender & Frequency & Percent \\
\hline Male & 62 & 51.7 \\
\hline Female & 58 & 48.3 \\
\hline Total & 120 & 100.0 \\
\hline
\end{tabular}


Table 3. The Frequency Distribution of Subjects Regarding Grades of Study

\begin{tabular}{|l|c|c|c|}
\hline \multicolumn{1}{|c|}{ Grade } & Frequency & Percent & Cumulative Percent \\
\hline Elementary & 32 & 26.7 & 26.7 \\
\hline Guidance & 29 & 24.2 & 50.8 \\
\hline High school & 31 & 25.8 & 76.7 \\
\hline University & 28 & 23.3 & 100 \\
\hline Total & 120 & 100 & \\
\hline
\end{tabular}

Table 4. Descriptive Frequency Distribution of Subjects Regarding Introversion and Extroversion

\begin{tabular}{|l|c|c|}
\hline \multicolumn{1}{|c|}{ Personality } & Frequency & Percent \\
\hline Extroversion & 53 & 44.2 \\
\hline Introversion & 67 & 55.8 \\
\hline Total & 120 & 100 \\
\hline
\end{tabular}

Table 5. Descriptive Statistical Indices Related to Introvert and Extrovert Subjects

\begin{tabular}{|l|c|c|c|c|c|c|}
\hline Personality & Mean & Std. Deviation & Mean Std. Error & Range & Maximum & Minimum \\
\hline Introvert & 16.15 & 2.205 & 0.303 & 9 & 22 & 13 \\
\hline Extrovert & 8.58 & 2.388 & 0.292 & 9 & 12 & 3 \\
\hline Total & 11.93 & 4.420 & 0.403 & 19 & 22 & 3 \\
\hline
\end{tabular}

Table 6. Statistical Indices Related to Introvert and Extrovert Subjects Regarding their Listening Ability

\begin{tabular}{|l|c|c|c|c|c|c|}
\hline Listening ability & Mean & Std. Deviation & Mean Std. Error & Range & Maximum & Minimum \\
\hline Introvert & 4.70 & 0.668 & 0.092 & 2 & 5 & 3 \\
\hline Extrovert & 1.73 & 1.024 & 0.125 & 4 & 5 & 1 \\
\hline Total & 3.04 & 1.722 & 0.157 & 4 & 5 & 1 \\
\hline
\end{tabular}

Table 7. The Correlation between Introversion/Extroversion and Subjects' Listening Ability

\begin{tabular}{|c|c|c|c|c|}
\hline Variable & Number & $\begin{array}{c}\text { Pearson Correlation } \\
\text { Coefficient }\end{array}$ & Sig & $\begin{array}{c}\text { Confirmed } \\
\text { or Rejected }\end{array}$ \\
\hline $\begin{array}{l}\text { Introversion and Extroversion } \\
\text { in Listening Ability }\end{array}$ & 120 & 0.718 & 0.000 & confirmed \\
\hline
\end{tabular}

Table 8. The Results of Two-Way ANOVA Regarding Subjects' Gender

\begin{tabular}{|l|c|c|c|c|c|c|}
\hline \multicolumn{1}{|c|}{ Source } & $\begin{array}{c}\text { Sum of } \\
\text { Squares }\end{array}$ & df & $\begin{array}{c}\text { Mean } \\
\text { Square }\end{array}$ & F & Sig & $\begin{array}{c}\text { Partial Eta } \\
\text { Squared }\end{array}$ \\
\hline Personality & 260.346 & 1 & 260.346 & 331 & 0.0005 & 0.740 \\
\hline Gender & 1.076 & 1 & 1.070 & 1.368 & 0.244 & 0.012 \\
\hline Personality\& Gender & 0.065 & 1 & 0.065 & 0.065 & 0.773 & 0.001 \\
\hline Error & 91.239 & 116 & 0.787 & & & \\
\hline
\end{tabular}


Table 9. The Results of Two-way ANOVA Test Regarding Subjects' Age

\begin{tabular}{|l|c|c|c|c|c|c|}
\hline \multicolumn{1}{|c|}{ Source } & Sum of squares & df & Mean Square & F & Sig & $\begin{array}{c}\text { Partial Eta } \\
\text { Squared }\end{array}$ \\
\hline Personality & 210.773 & 1 & 210.773 & 343.612 & 0.0005 & 0.754 \\
\hline Age & 13.252 & 3 & 4.417 & 7.180 & 0.0005 & 0.161 \\
\hline Personality\& age & 4.176 & 3 & 1.392 & 2.263 & 0.008 & 0.057 \\
\hline Error & 68.902 & 112 & 0.615 & & & \\
\hline
\end{tabular}

Table 10. LSD Test Run for Checking Similar Sub-groups Regarding Subjects' Personality \&Age

\begin{tabular}{|c|c|c|}
\hline Subjects' Age & Number & $\begin{array}{c}\text { Mean of Groups at } \\
\mathbf{A}=\mathbf{0 . 0 5}\end{array}$ \\
\cline { 3 - 3 } & & 1 \\
\hline $8-10$ & 30 & 10.1667 \\
$11-14$ & 31 & 11.7308 \\
$15-18$ & 33 & 12.4516 \\
$19-22$ & 26 & 13.1818 \\
\hline Level of Significance & & 0.070 \\
\hline
\end{tabular}

Table 11. The Results of Two-way ANOVA Test Regarding Participants' Grades

\begin{tabular}{|l|c|c|c|c|c|c|}
\hline \multicolumn{1}{|c|}{ Source } & $\begin{array}{c}\text { Sum of } \\
\text { Squares }\end{array}$ & df & $\begin{array}{c}\text { Mean } \\
\text { Square }\end{array}$ & F & Sig & $\begin{array}{c}\text { Partial Eta } \\
\text { Squared }\end{array}$ \\
\hline Personality & 133.836 & 1 & 133.836 & 227.448 & 0.0005 & 0.670 \\
\hline Grade Of Study & 15.401 & 3 & 5.134 & 8.724 & 0.0005 & 0.189 \\
\hline Personality\& Grade & 6.565 & 3 & 2.188 & 3.719 & 0.014 & 0.091 \\
\hline Error & 65.903 & 112 & 0.588 & & & \\
\hline
\end{tabular}

Table 12. LSD Test Run for Checking the Similar Sub-groups Regarding Subjects' Personality \& Grades

\begin{tabular}{|l|c|c|c|}
\hline \multicolumn{1}{|c|}{$\begin{array}{c}\text { Subjects' Grades of } \\
\text { Study }\end{array}$} & Number & \multicolumn{2}{|c|}{$\begin{array}{c}\text { Mean of Groups at } \\
\text { A= 0.05 }\end{array}$} \\
\cline { 3 - 4 } & & 1 & 2 \\
\hline Elementary & 32 & 8.9062 & \\
Guidance School & 29 & & 12.7241 \\
High School & 31 & & 12.7419 \\
University & 28 & & 13.6429 \\
\hline Level of Significance & & 1.00 & 0.857 \\
\hline
\end{tabular}




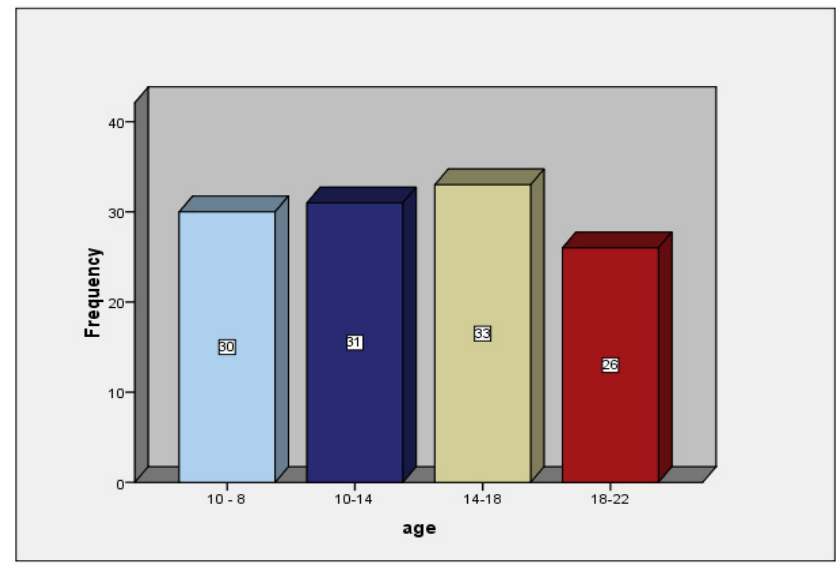

Figure 1. The Column Figure of Subjects Regarding Age

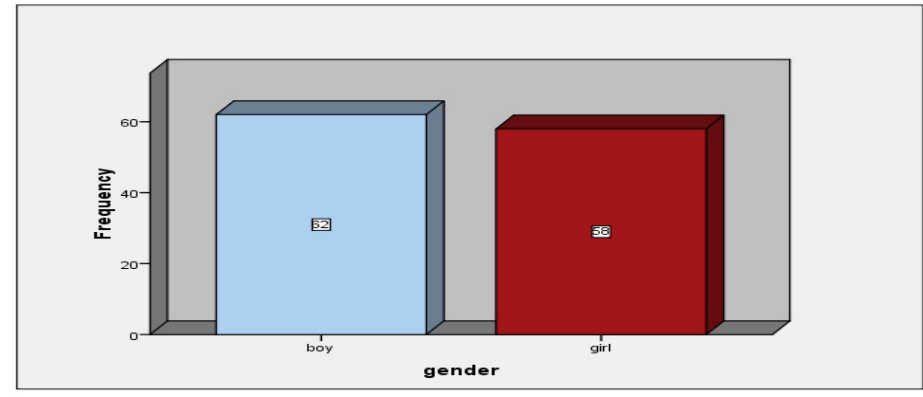

Figure 2. The Column Figure of Intermediate EFL Learners Regarding Gender

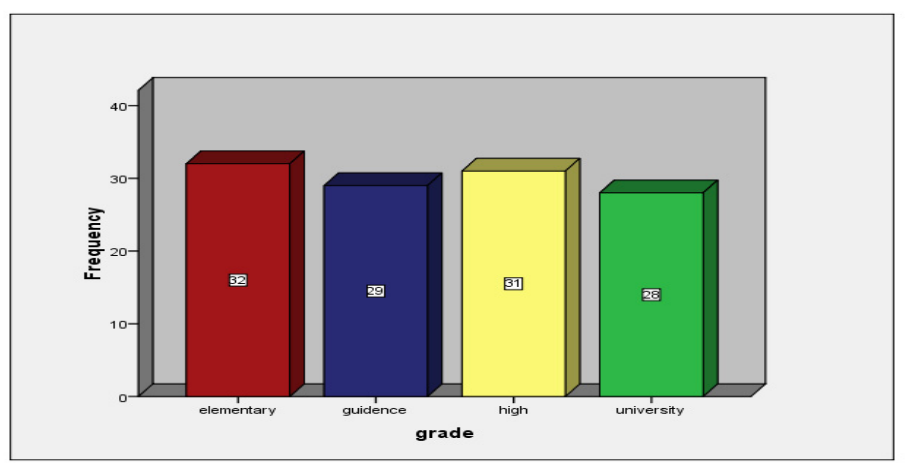

Figure 3. The Column Figure of Subjects Regarding Grades of Study 


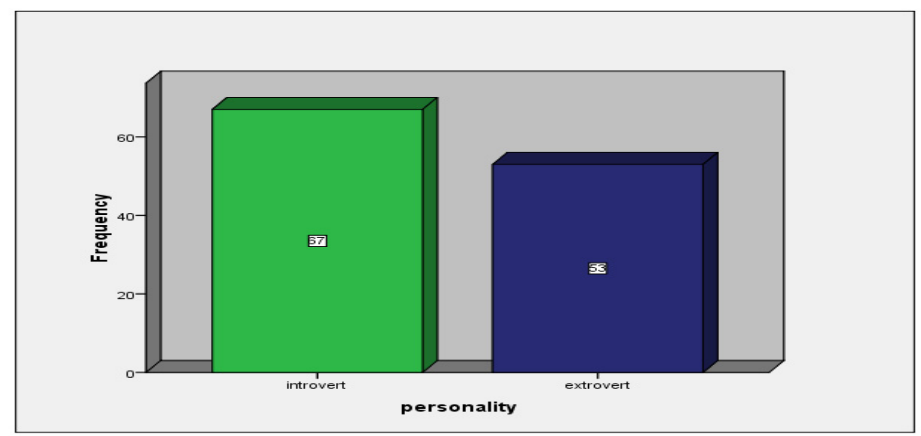

Figure 4. The Column Figure of Subjects Regarding their Introversion and Extroversion

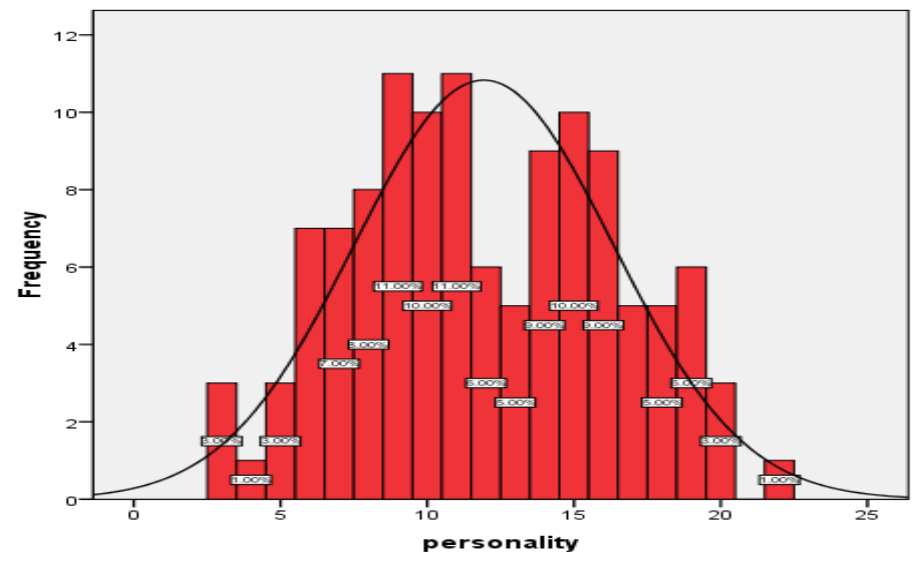

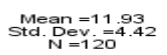

Figure 5. The Histogram Figure of Subjects' Introversion and Extroversion Features

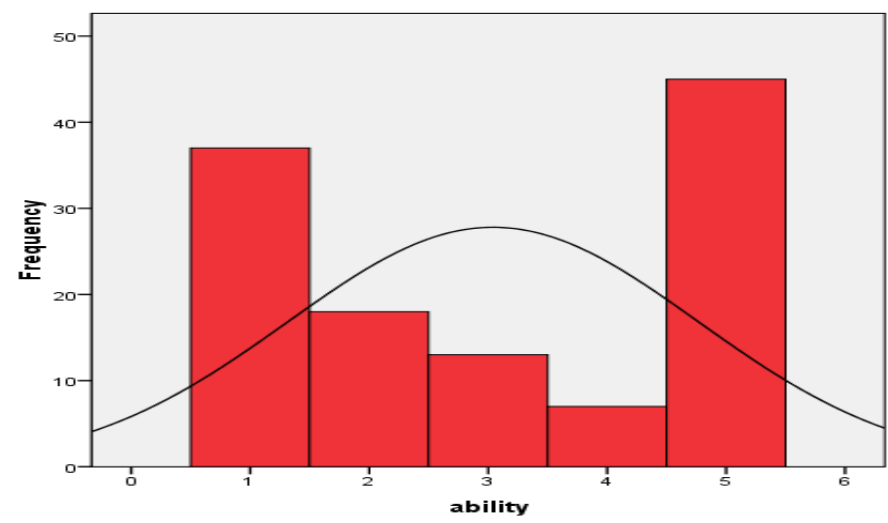

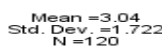

Figure 6. The Histogram Figure of Introvert and Extrovert Subjects Regarding their Listening Ability 